\title{
LIMITES E POSSIBILIDADES NA EFETIVAÇÃO DO CONTROLE SOCIAL
}

\author{
Silvia Aline Silva Ferreira ${ }^{1}$, Joice Noeli Ferreira Rodrigues ${ }^{2}$ \\ ${ }^{1}$ Faculdades Adamantinenses Integradas - FAl, curso de Serviço Social, Adamantina, SP. ${ }^{2}$ Assistente Social. E-mail: \\ silviaaline @hotmail.com
}

\begin{abstract}
RESUMO
A Assistência Social tem sua origem nos tempos mais remotos caracterizada como caridade e benevolência, porém, é com a Constituição Federal de 1988 que esta é caracterizada enquanto política pública e responsabilidade do Estado, a referida Constituição também prevê a participação da população e abre caminhos para a promulgação da Lei Orgânica de Assistência Social, sancionada no de 1993, que cria os Conselhos de Assistência Social como instâncias deliberativas e espaços para participação popular que se realizará através do controle social. O presente trabalho descreve a importância dos Conselhos de Assistência Social na Política de Assistência Social, especificamente o Conselho Municipal de Assistência Social do município de Bastos, abordando ações e desafios a serem superados para concretização do controle social.
\end{abstract}

Palavras-chave: Política de Assistência Social. Controle Social. Conselho de Assistência Social.

\section{LIMITS AND POSSIBILITIES IN THE EFFECTIVE OF SOCIAL CONTROL}

\begin{abstract}
The Social Assistance has its origin in ancient times characterized as charity and benevolence, however, is with the Federal Constitution of 1988 that is characterized as a public policy and state responsibility, that constitution also provides for the participation of the population and opens the way for the enactment of the Organic Law of social assistance, passed in 1993, establishing the social assistance councils as deliberative bodies and spaces for popular participation to be held through social control. This paper describes the importance of the Social Welfare Council in the Social Assistance Policy, specifically the Municipal Council of Social Welfare of the municipality of Bastos, addressing actions and challenges to be overcome to achieve social control.
\end{abstract}

Keywords: Social Assistance Policy. Social control. Council of Social Welfare. 


\section{INTROUÇÃO}

Os Conselhos de Assistência Social, criados pela Lei no 8.742 de 07 de dezembro de 1993 (Lei Orgânica de Assistência Social), são importantes dispositivos na gestão da Política de Assistência Social, caracterizada como política pública após a promulgação da Constituição Federal de 1988, são constituídos enquanto espaços democráticos, compostos de forma permanente e paritária, com funções deliberativas e fiscalizadoras, além de se configurarem como uma das formas de participação popular, criando mecanismos em sua organização para o exercício do controle social, conforme prevê as legislações vigentes.

O intuito deste trabalho é apresentar o Conselho Municipal de Assistência Social como instrumento do controle social na Política de Assistência Social do município de Bastos, mensurando as ações e os desafios a serem superados pelo do Conselho Municipal de Assistência Social do município de Bastos em sua organização para que de fato se concretize enquanto espaço para o exercício do controle social.

\section{A CONSTITUIÇÃO FEDERAL DE 1988 E O CONTROLE SOCIAL}

A Constituição Federal de 1988, promulgada no dia 05 de outubro, representa um grande marco para o processo de redemocratização no Brasil no campo dos direitos civis, políticos e sociais, vigora até os dias atuais e norteia as leis e dispositivos do nosso país.

Entre os importantes avanços, ressaltamos aqui a Assistência Social que, passa a integrar o tripé da Seguridade Social, juntamente com a saúde e a previdência social e de acordo com o artigo 203 do texto constitucional, "será prestada a quem dela necessitar, independentemente de contribuição à seguridade social" (BRASIL, 1988), bem como responsabiliza o Estado na elaboração e execução da assistência social.

Ainda na área da assistência social, a Constituição, artigo 204, prevê "a participação da população, por meio de organizações representativas, na formulação das políticas e no controle das ações em todos os níveis" (BRASIL, 1988). Nesta ótica de participação popular preconizada nos princípios da Constituição Federal, o controle social surge como uma das principais formas de participação da sociedade de forma articulada, Bravo e Correia afirmam que:

No Brasil, a expressão controle social tem sido utilizada como sinônimo de controle da sociedade civil sobre as ações do Estado, especificamente no campo das políticas sociais, desde o período da redemocratização dos anos de 1980. A utilização da expressão com este sentido foi propiciada pela conjuntura de lutas políticas pela democratização do país frente ao Estado autoritário, implantado a partir da ditadura militar (2012, p.127). 
Nesta concepção, o controle social pode ser entendido como a participação da população na gestão pública que garante aos cidadãos espaços para influir nas políticas públicas, além de possibilitar o acompanhamento, a avaliação e a fiscalização das instituições públicas, visando assegurar os interesses coletivos.

Surgem então, os conselhos como espaço de participação popular nas políticas públicas, no qual discorremos posteriormente, especificamente no que refere-se a Política de Assistência Social, ressaltando as ações e desafios para efetivação do Controle Social através das ações do Conselho Municipal de Assistência Social no município de Bastos.

Esclarecemos que, o termo "controle social" abordado nesse trabalho refere-se a participação da população na Política de Assistência Social, e sendo o Conselho de Assistência Social, um dos mecanismos de participação, elucidaremos o controle social nesse contexto.

Partindo da Constituição Federal, surge então, em 1993, a Lei Orgânica de Assistência Social, essa regulamenta a Política de Assistência no Brasil Social de forma estruturada, descentralizada e participativa no formato de Lei Federal, e trata inclusive da criação dos Conselhos de Assistência Social e reafirma a participação da população como uma de suas diretrizes.

Esclarecemos que as conferências, assim como os conselhos, embora não sejam os únicos, também se constituem espaço para o exercício do controle social, de acordo com Bravo:

As conferências são eventos que devem ser realizados periodicamente para discutir as políticas sociais de cada esfera e propor diretrizes de ação. As deliberações das conferências devem ser entendidas enquanto norteadoras da implantação das políticas e, portanto, influencias as discussões travadas nos diversos conselhos (2009, p. 397).

A NOB/SUAS, elenca atribuições dos Conselhos de Assistência Social e determina aos mesmos o planejamento de suas responsabilidades, visando a continuidade de suas ações e o exercício do controle social, as quais abordaremos no próximo capítulo.

\section{LIMITES E POSSIBILIDADES NA EFETIVAÇÃO DO CONTROLE SOCIAL NO MUNICÍPIO DE BASTOS/SP}

Para mensurarmos as ações e desafios para efetivação do controle social no Conselho Municipal de Assistência Social de Bastos, realizamos leitura dos dispositivos municipais vigentes pertinentes ao Conselho de Assistência Social (Leis Municipal 1.243/96, 2.332/11 e 1.759/04, Portaria 680/96 e Decreto 769/11) e no período de 30 de setembro a 07 de outubro de 2014, doze conselheiros, entre eles titulares e suplentes e a secretária executiva do CMAS responderam ao 
questionário por nós aplicado, composto por perguntas fechadas com alternativas correspondentes ao intuito deste trabalho, ao final do questionário aplicado, apresentamos uma pergunta aberta de cunho opcional.

O Conselho Municipal de Assistência Social de Bastos foi instituído no ano de 1996, pela Lei Municipal no 1.243 de 12 de janeiro, em conformidade com a Lei Federal 8.742/93 - LOAS, sobre a criação dos Conselhos, vinculado à Secretaria Municipal de Promoção Social, que é responsável pela coordenação da Política de Assistência do Município.

Notamos através da pesquisa que, em sua organização o Conselho Municipal de Assistência Social, apresenta pontos positivos para efetivação do controle social, porém, existem desafios a serem superados, visando totalizar a concretização do Conselho de Assistência enquanto espaço do exercício do controle social na Política de Assistência Social do Munícipio de Bastos.

\subsection{As ações para efetivação do Controle Social no Conselho Municipal de Assistência Social de} Bastos.

O Conselho Municipal de Assistência Social no município de Bastos é composto de forma paritária, conforme preceitua a Lei Orgânica de Assistência Social, constituindo um espaço democrático. As reuniões do Conselho, de caráter ordinário, ocorrem mensalmente na sede da Secretaria Municipal de Promoção Social. Para melhor fortalecimento dos Conselhos de Assistência Social sabemos que é necessário um assessoramento técnico aos seus membros, que possa instruí-los e auxiliá-los de maneira neutra nas deliberações, que se iniciam de forma individual, e por fim se constituem um acordo coletivo, neste quesito, dez dos conselheiros, ou seja, 79,9\%, responderam afirmativo quanto a existência dessa assessoria, fato que favorece o fortalecimento do Conselho.

Constatamos através das respostas afirmativas de doze, dos treze conselheiros que responderam ao questionário, que há articulação entre o Conselho e o Órgão Gestor de Bastos Secretaria Municipal de Promoção Social quanto a articulação na definição de padrões de qualidade de atendimento, bem como no estabelecimento de critérios para o repasse de recurso financeiros, inclusive, as respostas foram as mesmas quanto o conhecimento dos conselheiros dos recursos disponíveis destinados a Política de Assistência do Município através do Fundo Municipal de Assistência Social ${ }^{1}$.

\footnotetext{
${ }^{1}$ O Fundo Municipal de Assistência Social de Bastos foi instituído pela Lei Municipal no1243/96 e tem como objetivo captar e facilitar o repasse e a aplicação de recursos destinados aos programas de assistência social desenvolvidas no município de acordo com as propostas de ação elaboradas pelo CMAS.
} 
Porém é notável que, para o Conselho se consolidar enquanto espaço democrático e participativo, algumas ações necessitam ser aprimoradas e implementadas, a seguir, apresentaremos alguns desafios a serem superados neste sentido.

Um dos mecanismos de sintetizar e registrar as deliberações das reuniões do Conselho é a elaboração de Ata, e sem dúvidas, a publicização da mesma torna-se um instrumento de clareza nos atos dos conselhos, porém, constatamos que não há mecanismos de publicação das Atas, já que, o Conselho deveria se organizar para que suas deliberações tornassem público e chegassem ao conhecimentos de todos.

Os dados acima mostram que a publicização da Ata só é feita na reunião posterior, sendo lida aos que estiverem presentes, porém, acreditamos que todos os sujeitos envolvidos, não só os membros, devem estar cientes das deliberações do Conselho, conjecturando, como afirma Raichelis (1998, p.83) "a publicidade e fidedignidade das informações que orientam as deliberações nos espaços públicos de representação". Para exercício do controle social, os conselheiros devem estar capacitados e compreenderem sua atuação dentro do Sistema Único de Assistência Social e vislumbrarem a Assistência Social enquanto direito, na ocasião da pesquisa, seis dos conselheiros ainda não haviam participado de capacitações exclusivas para membros do Conselho.

A capacitação permite, além do conhecimento de suas atribuições, esclarecer os acompanhamentos que deverão ser efetuados pelo Conselho, pois este também possui caráter fiscalizador, não sendo o único responsável pela fiscalização da Política de Assistência no município que pode ser efetuada pelo Tribunal de Contas, Câmara dos Vereadores e Ministério Público, porém questionados sobre o conhecimento referentes às ações desenvolvidas no município abrangente da Política de Assistência Social, apenas um dos conselheiros afirmou ter muito conhecimento quanto as ações, representando 85 , sendo que $46 \%$ afirmaram ter pouco conhecimento e os demais $46 \%$ afirmaram ter conhecimento médio.

As entidades e organizações de assistência social, junto com os entes federados e Conselhos de Assistência, integra o SUAS, a atuação do Conselho inclui o acompanhamento e fiscalização das referidas entidades e organizações, que somente poderão funcionar mediante prévia inscrição no Conselho de Assistência Social (BRASIL, LOAS, 1993).

No questionário, oito conselheiros, responderam que não há a fiscalização assídua dos serviços ofertados pelas instituições com inscrição no CMAS de Bastos, caracterizando mais um desafio a ser superado, não apenas quanto a fiscalização, pois antes dessa, é necessário um 
assessoramento e orientação às entidades que desenvolvem serviços socioassistenciais, a exemplo do que ocorre no CMAS de Bastos.

No questionário elucidamos o controle social entendido como participação da população na gestão pública que garante aos cidadãos espaços para influir nas políticas públicas, que permite a possibilidade de acompanhamento, avaliação e fiscalização das políticas pública, no caso a de Assistência Social, visando assegurar os interesses coletivos, e questionamos se os conselheiros vislumbravam o CMAS como uma ferramenta de participação popular, as respostas se relacionam com os quesitos de sentir-se a vontade para expor opiniões em reuniões e neutralidade nas deliberações, já que são pontos divergentes na visão dos conselheiros, neste caso, oito responderam positivo e cinco acreditam que o conselho não está sendo uma forma de participação popular.

Como citamos anteriormente, o questionário contou com uma questão opcional, para que os conselheiros apontassem sugestões para melhoria da Política de Assistência Social através da atuação do CMAS, destacamos duas das cinco obtidas, que se mostram desafios a serem superados:

"É fundamental a participação de todos os conselheiros para o bom desempenho deste conselho! Pessoas incapacitadas para exercer participação, independente da justificativa, deveriam ser substituídas!" (Conselheiro 1).

Mais orientações de técnicos capacitados para capacitar quem executa os serviços" (Conselheiro 2).

A resposta do Conselheiro 1, externa a preocupação do mesmo quanto a capacitação dos membros, inclusive participação de todos para o bom desempenho do Conselho, essa colocação do conselheiro é pertinente, sendo fundamental para efetivação do controle social, e concordamos no quesito de capacitação para exercício dessa função, porém a substituição por falta de capacitação de forma arbitrária não é justificável, pois o Órgão Gestor deve proporcionar capacitação para os membros do conselho através dos recursos financeiros destinados para esse fim, conforme previsão da NOB/SUAS 2012 , artigo 123 §3: “Os órgãos gestores devem promover e incentivar a capacitação continuada dos conselheiros, conforme plano de capacitação"(BRASIL, 2012).

\section{CONSIDERAÇÕES FINAIS:}

No presente trabalho apresentamos alguns pontos na organização do Conselho de Assistência Social do município de Bastos, que favorecem a efetivação do exercício do controle social. 
Sabemos que criação do Conselho de Assistência por si só não garante a efetividade de suas ações, inclusive do controle social, sendo necessário a superação de alguns desafios em sua organização e atuação, no CMAS de Bastos, identificamos os seguintes: a publicização dos Atas das reuniões do Conselho, que se faz necessário para transparência e conhecimento público das deliberações efetuadas pelo Conselho; capacitação dos conselheiros, para que estes tenham conhecimento da Política de Assistência Social e de suas competências enquanto conselheiro, para que sua atuação ocorra de forma assídua e ativa, pois a maioria dos conselheiros ainda consideram sua atuação regular; fiscalização das entidades e organizações de assistência social que são integrantes do SUAS, não basta a realização da inscrição, é necessário o acompanhamento destas, visando criar e manter a qualidade nos serviços que são prestados aos usuários; interação entre os conselhos de outras áreas, já que a Assistência Social não se efetiva de forma isolada.

Fortalecer as ações que já são desenvolvidas pelo Conselhos de Assistência Social de Bastos e superar os desafios é necessário, para que esse se fortaleça no município como uma instância deliberativa do SUAS conforme preconiza a Lei Orgânica de Assistência Social, e seja vislumbrado como espaço democrático e participativo pelos próprios conselheiros, população e Poder Executivo, se constituindo espaço de exercício do controle social, primando, conforme orienta Norma Operacional Básica do SUAS pela efetividade e transparência das suas atividades.

\section{REFERÊNCIAS}

BRASIL. Constituição (1988). Constituição da República Federativa do Brasil. Brasília, DF: Senado, 1988.

BRASIL (2005). Ministério de Desenvolvimento Social e Combate à Fome, NOB/SUAS. Resolução CNAS no 130, de 15 de julho de 2005, publicada no DOU.Brasília.

Ministério de Desenvolvimento Social e Combate à Fome, Política Nacional de Assistência Social (PNAS) - Brasília, Secretaria Nacional de Assistência Social, novembro de 2004.

1993b.

. Lei n. 8.742, de 7 de dezembro de 1993. Lei Orgânica da Assistência Social. Brasília,

BRAVO, Maria Inês Souza. O trabalho do assistente social nas instâncias públicas de controle democrático. In: Capacitação em Serviço Social: direitos sociais e competências profissionais. Unidade 4. Brasília: CFESS/ ABEPPS/ CEAD-UNB, 2009.

CAMPOS, Edval Bernardino. Assistência Social: Do descontrole ao controle social. Revista Serviço Social e Sociedade n. 88, São Paulo: Cortez, 2006.

RAICHELIS, Raquel. A assistência social e a esfera publica: os conselhos no exercício do controle social. Serviço Social e Sociedade. São Paulo: n.56, p. 77- 96, mar. 1998. 
Esfera pública e Conselhos de Assistência Social: caminhos da construção democrática. São Paulo: Cortez, 1998.

Sistema Único de Assistência Social - SUAS (disponível em http://www.mds.gov.br/suas/redesuas/rede-suas), pesquisado em 15/05/2011. 